\title{
Microscopic Origin of Strength and Microhardness of Titanium Alloy at Elevated Temperature
}

M. Islam ${ }^{1}$, C. Fermin ${ }^{1}$ and H. Aglan ${ }^{1}$

${ }^{1}$ Tuskegee University, Tuskegee, AL 36088 USA

Titanium alloys are promising materials for use in extreme environments especially in nuclear fusion and fission reactor systems, biomedical applications, aerospace and high temperature industrial applications [1]-[2]. In this study the influence of environmental temperatures up to $900^{\circ} \mathrm{C}$ on the mechanical properties of dual phase Ti-6Al-4V alloy was investigated. The origin of strength at room temperature and lack of ductility after elevated temperature exposure were identified microscopically.

The titanium alloy used in this study was cold rolled Ti-6Al-4V (Grade 5) sheet of thickness $0.81 \mathrm{~mm}$. The specimens were heated in a vacuum furnace at temperatures of $450^{\circ} \mathrm{C}$ and $900^{\circ} \mathrm{C}$. A ramp rate of 5 ${ }^{\circ} \mathrm{C} / \mathrm{min}$, hold time for 2 hours, and then cool down to room temperature at a rate of $1{ }^{\circ} \mathrm{C} / \mathrm{min}$ were used. Tensile tests were carried out at room temperature using an MTS 810 Servo-hydraulic Machine at a cross head speed of $0.02 \mathrm{~mm} / \mathrm{s}$. The fracture surfaces were examined with a Hitachi S-3400N SEM. Specimens were polished and etched in a metallographic Keller's reagent composed of $2.5 \% \mathrm{HNO}_{3}$, $1.5 \% \mathrm{HCl}, 1 \% \mathrm{HF}$, and $95 \%$ distilled water for optical microstructure studies.

The ultimate tensile stress, yield stress, elongation, and microhardness as functions of environmental temperature were evaluated. The tensile strength and elongation were not affected after the $450^{\circ} \mathrm{C}$ exposure. After $900^{\circ} \mathrm{C}$, the tensile strength and elongation dropped by $25 \%$ and $88 \%$, respectively. The microhardness was increased by $44 \%$, from HRC 36 to 52, from their room temperature values.

The microstructure of the Ti-6Al-4V alloy showed a randomly distributed equiaxed structure, composed of alpha grains around 5-20 $\mu \mathrm{m}$ and surrounded by intergranular $\beta$ phase with bands of $0.5-1 \mu \mathrm{m}$ width and 2-5 $\mu \mathrm{m}$ elongated structure. The alpha stabilizer $(6 \% \mathrm{Al})$ produced coherent ordered $\alpha_{2}$ phase $\left(\mathrm{Ti}_{3} \mathrm{Al}\right)$ to strengthen the structure (Figure $2 \mathrm{a}$ black arrow). The $\beta$ stabilizer $(4 \% \mathrm{~V})$ was dispersed in the phase structure (Figure 1a and $2 \mathrm{a}$ red arrows). The volume fraction of the $\beta$ phase was around $35 \%$ at room temperature and after $450^{\circ} \mathrm{C}$ exposure.

After $900^{\circ} \mathrm{C}$ exposure for 2 hours, partial phase transformation of HCP to BCC occurred and the $\beta$ phase transformed to primary alpha grains $\left(\mathrm{Ti}_{3} \mathrm{Al}\right)$. Some acicular $\beta$ grains of 5-10 $\mu \mathrm{m}$ in length and $0.05-1 \mu \mathrm{m}$ in width were observed and the volume fraction was reduced by $10-15 \%$. The material became brittle because the formation of $\mathrm{Ti}_{3} \mathrm{Al}$ increased (Figure 3a white area). This was a major contributor to the ductility loss which is supported by Wang et al.[3].

Optical and SEM micrographs at different temperatures are given in Figures 1-3 that reveal ductile dimple features were dominant. The dimple size became larger and deeper with increasing the environmental temperature. The average dimple size was between 3-6 $\mu \mathrm{m}$ for both room temperature and $450^{\circ} \mathrm{C}$. After $900^{\circ} \mathrm{C}$ exposure for two hours, the dimples were significantly larger $(30-40 \mu \mathrm{m})$.

\section{References}

[1] M Victoria et al., Structural materials for fusion reactors, Nuclear Fusion, 41(8), (2001) p. 1047.

[2] I Gurrappa, Characterization of titanium alloy Ti-6Al-4V for chemical, marine and industrial applications. Materials Characterization, 51(2), (2003)p. 131-139.

[3] SH Wang et al., Tensile properties of LBW welds in Ti-6Al-4V alloy at evaluated temperatures below 450 C. Materials Letters, 57(12), (2003) p. 1815-1823.

[4] Supported by NSF; Partnerships for International Research and Education (PIRE) program. 

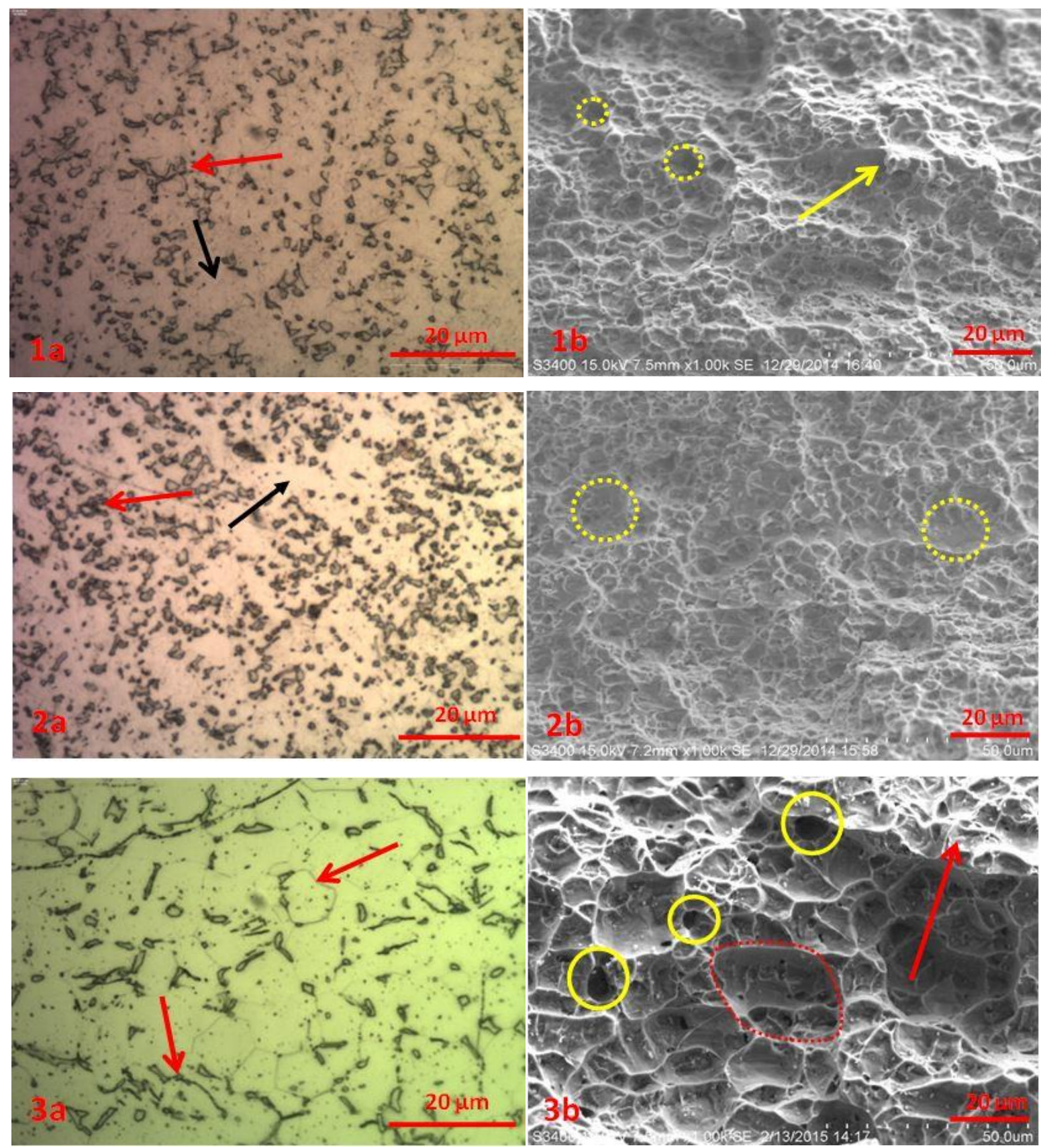

Figure 1. Optical (1a) and SEM (1b) micrographs of the Ti-6Al-4V metal at room temperature. Alpha phase (black arrow) and beta phase (red arrow), Figure 1a. Dimple structure (yellow discontinuous circle) and pulled up strip features (yellow arrow), Figure $1 \mathrm{~b}$.

Figure 2. Optical (2a) and SEM (2b) micrographs after $450^{\circ} \mathrm{C}$ exposure. Few large dimples (yellow discontinuous circle), Figure 2b.

Figure 3. Optical (3a) and SEM (3b) micrographs after $900^{\circ} \mathrm{C}$ exposure. Acicular $\beta$ grains (bottom red arrow) and primary $\alpha$ grains of $10-15 \mu \mathrm{m}$ size (top red arrow), Figure 3a. Large dimples (red discontinuous circle), voids (yellow continuous circles), and brittle like fracture facets (red arrow), Figure 3 b. An $88 \%$ reduction in elongation is associated with these fracture features. 